\title{
Analysis of Surgical Mortality for Congenital Heart Defects Using RACHS-1 Risk Score in a Brazilian Single Center
}

Candice Torres de Melo Bezerra Cavalcante1 , MSc; Nayana Maria Gomes de Souza'1, PT; Valdester Cavalcante Pinto Júnior ${ }^{1}, \mathrm{MD}$, PhD; Klébia Magalhães Pereira Castello Branco', PhD; Ronald Guedes Pompeu'; Andreia Consuelo de Oliveira Teles', MD; Rodrigo Cardoso Cavalcante'; Giselle Viana de Andrade', PT, MD

\section{Abstract}

Introduction: Risk Adjustment for Congenital Heart Surgery 1 (RACHS-1) score is a simple model that can be easily applied and has been widely used for mortality comparison among pediatric cardiovascular services. It is based on the categorization of several surgical palliative or corrective procedures, which have similar mortality in the treatment of congenital heart disease.

Objective: To analyze the in-hospital mortality in pediatric patients ( $<18$ years) submitted to cardiac surgery for congenital heart disease based on RACHS-1 score, during a 12-year period.

Methods: A retrospective date analysis was performed from January 2003 to December 2014. The survey was divided in two periods of six years long each, to check for any improvement in the results. We evaluated the numbers of procedures performed, complexity of surgery and hospital mortality.
Results: Three thousand and two hundred and one surgeries were performed. Of these, 3071 were able to be classified according to the score RACHS-1. Among the patients, $51.7 \%$ were male and $47.5 \%$ were younger than one year of age. The most common RACHS-1 category was $3(35.5 \%)$. The mortality was $1.8 \%, 5.5 \%, 14.9 \%, 32.5 \%$ and $68.6 \%$ for category $1,2,3,4$ and 6 , respectively. There was a significant increase in the number of surgeries $(48 \%)$ and a significant reduction in the mortality in the last period analysed $(13.3 \%$ in period $I$ and $10.4 \%$ in period II; $P=0.014$ ).

Conclusion: RACHS-1 score was a useful score for mortality risk in our service, although we are aware that other factors have an impact on the total mortality.

Keywords: Congenital Heart Disease. Mortality. Risk Adjustment. Surgery.

\section{Abbreviations, acronyms \& symbols}

CPB = Cardiopulmonary bypass

RACHS-1 = Risk Adjustment for Congenital Heart Surgery 1

ROC = Receiver operating characteristic

SPSS = Statistical Package for Social Sciences

\section{INTRODUCTION}

Congenital heart defects are the most common cause of congenital anomalies, representing a global health problem, with overall incidence of $28 \%$ of all major congenital anomalies ${ }^{[1]}$. The overall prevalence of congenital heart defects at birth increased substantially and is estimated at 9 per 1,000 live births

\section{'Hospital de Messejana Dr. Carlos Alberto Studart Gomes, Fortaleza, CE, Brazil.}

This study was carried out at the Hospital de Messejana Dr. Carlos Alberto Studart Gomes, Fortaleza, CE, Brazil. over the last 15 years. This corresponds to 1.35 million newborns with congenital heart disease each year ${ }^{[1]}$.

The estimate for congenital heart disease in Brazil is 25,757 new cases per year. In 2010, 1,377 cases of births were registered with congenital heart defects in the DATASUS/Ministry of Health, representing $5.3 \%$ of the estimated to Brazil[2]

Risk stratification in cardiac surgery is problematic due to large variations of the cases ${ }^{[3,4]}$. There are many surgical procedures that can be classified as palliative or corrective. Due to its high complexity, large number of congenital heart disease variants and few cases of each heart defect, it is difficult to establish a risk stratification system of nomenclature that is universally accepted ${ }^{[3]}$

Special attention in the literature is given to the study by Jenkins et al. ${ }^{[4]}$, which propose an easily applicable risk score, called Risk Adjustment for Congenital Heart Surgery 1 (RACHS-1), which was based on the categorization of several surgical

Correspondence Address:

Valdester Cavalcante Pinto Júnior Hospital de Messejana Dr. Carlos Alberto Studart Gomes

Av. Frei Cirilo, 3480 - Messejana - Fortaleza, CE, Brazil - Zip code: 60840-285 E-mail: incorcrianca@yahoo.com.br 
procedures, palliative or corrective, which had similar hospital mortality. Thus, the diseases have been divided into six categories according to the expected mortality for each ${ }^{[4]}$.

In order to review the mortality of surgical procedures performed by pediatric cardiology service of the Messejana Hospital during a period of 12 years of operation, its determinants and related factors, we used a comparison of the mortality of our institution with the expected mortality RACHS-1 risk score.

The aim of this study is to analyze the in-hospital mortality in children and adolescents after surgery for congenital heart defects from a pediatric cardiology service of a tertiary publish health center in Fortaleza, Ceará, Brazil, during its 12 years compared to RACHS-1 risk score.

\section{METHODS}

After approval by the Research Ethics Committee and Institutional Research, we performed a retrospective analysis of data from records of cardiovascular surgeries performed from January 2003 to December 2014 at the Messejana Hospital, Fortaleza, Brazil. Our sample consisted of patients with congenital or acquired heart disease in the pediatric age group (under 18 years) who underwent cardiovascular surgery (corrective or palliative). Exclusion criteria were patients transferred to another service due to the impossibility of knowing the final outcome and patients who underwent procedures that could not be categorized for not belonging to the group of surgeries previously described by the score (130 patients). The independent variables were age, weight, gender, presence of trisomy 21, diagnosis, type of surgery, use of cardiopulmonary bypass (CPB), category of the RACHS-1 score. The dependent variable was the in-hospital mortality.

Based on the Statute of Children and Adolescents, the patients were divided into four categories according to age: neonatal (1-28 days), $1^{\text {st }}$ year of life (29 days to less than 1 year), children (1-12 years) and adolescents (12 years and to under 18 years of age). Hospital mortality was considered only for cases that occurred during hospitalization, regardless of time, for not being possible the full knowledge of the deaths occurred after discharge. The RACHS-1 risk score was used to classify the population according to surgical risk. Patients who underwent more than one procedure during the same hospitalization had the score considered as complex.

The research was divided into two periods to evaluate the evolution of the service in the last twelve years, due to the availability of data only from 2003. The period I is defined as the first six years, from 2003 to 2008 and the period II from 2009 to 2014. We evaluated the number of procedures performed, complexity of surgery and hospital mortality.

Data were analyzed using SPSS (Statistical Package for Social Sciences) statistical software, version 22 for Windows. Descriptive statistics were performed in relation to the distribution of variables and characteristics of the study population. Univariate analyzes were performed to assess the relationship between demographic and clinical variables and the outcome (mortality).

Continuous data were analyzed by statistical KlomogorovSmirnov (KS) test for normality and the data considered normal were evaluated by Student's t-test and ANOVA; and categorical variables by the chi-square test $\left(x^{2}\right)$. Categorical variables were represented by absolute numbers and percentages (with a confidence interval to $95 \%$ of an estimate) and continuous data, by the mean or median with their respective dispersion measures. To assess the predictive capacity of RACHS-1 score for mortality, we used the Receiver Operating Characteristic (ROC) curve and the estimated area under it.

Because of the retrospective nature of the study, data on sex, age, mortality were not available for all patients. During the statistical analysis, some data crossing did not have similar number of total procedures.

\section{RESULTS}

During the study period, 3201 surgeries were performed. Of these, 3071 were classified according to the RACHS-1 score and 130 procedures could not be categorized by the score. Of the patients, 1643 (51.7\%) were male, aged less than 1 year of age 1523 (47.5\%) and 2281 (71.1\%) used CPB. The median weight was $8 \mathrm{~kg}$ (4 to $17.8 \mathrm{~kg}$ ). Demographic characteristics are shown in Table 1.

Table 1. Demographic characteristics of patients undergoing cardiovascular surgery between 2003-2014.

\begin{tabular}{l|c}
\hline Variables & Rate, (\%) \\
\hline $\begin{array}{l}\text { Gender } \\
\text { Female }\end{array}$ & $1532(48.3)$ \\
Male & $1643(51.7)$ \\
\hline Age & $351(10.9)$ \\
0-28 days & $1172(36.6)$ \\
29 days to 1 year & $1331(41.5)$ \\
$>1$ year to 12 years & $287(9.9)$ \\
$>12$ years to under 18 years of age & \\
\hline Weight & $8 \mathrm{~kg}(4-17.8 \mathrm{~kg})$ \\
Median (IQ) & \\
\hline Trisomy 21 & $3015(94.5)$ \\
No & $177(5.5)$ \\
Yes & \\
\hline CPB & $2281(71.1)$ \\
With CPB & $917(28.6)$ \\
Without CPB &
\end{tabular}

$\mathrm{IQ}=$ inter-quartile range; $\mathrm{CPB}=$ cardiopulmonary bypass

There was a significant increase in the number of surgeries in the last six years, from 1238 to 1833 procedures $(P=0.001)$. This equates to a $48 \%$ increase in the total number of surgeries, with growth in all categories of RACHS- 1 score $(P=0.0001$; Figure 1$)$. Regarding the type of surgery, 2,281 (71.1\%) used CPB and the most common category of RACHS-1 was the 3 (1091/3071, 35.5\%). 


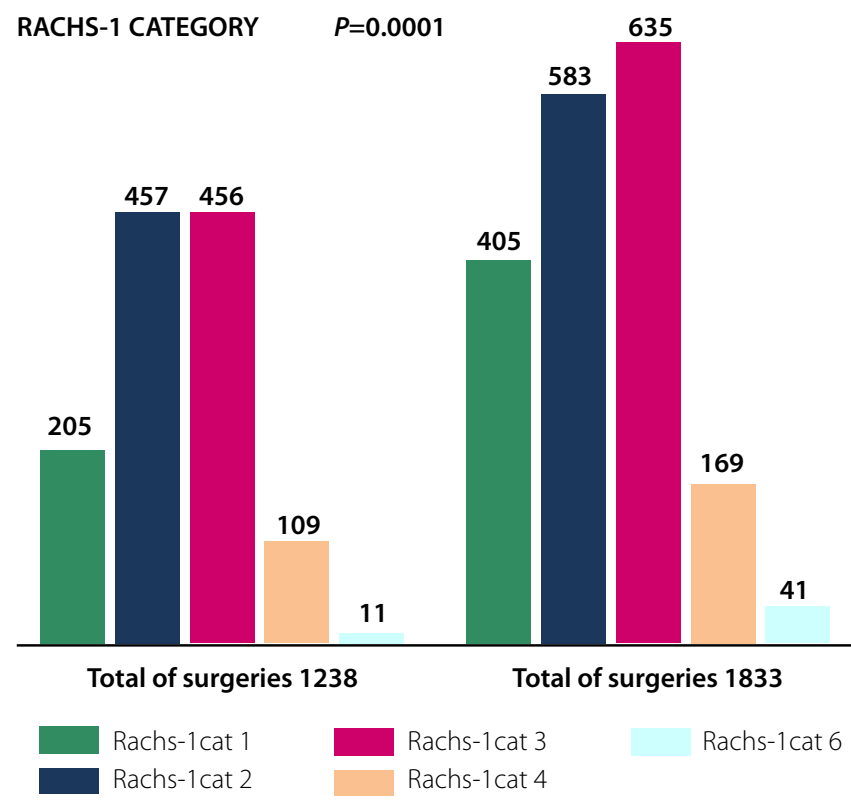

Fig. 1 - Distribution of surgeries according to the RACHS-1 score in both periods analyzed.

\section{RACHS-1 Category - Total of Surgeries}

The main procedures were ventriculoseptoplasty, pulmonary shunt, atrial septal defect and patent ductus arteriosus ligation (Figure 2).

Mortality also varied during the twelve years of records, with significant decrease despite an increase in the number of procedures, ranging from 13.3\% (171/1288) to 10.4\% (191/1889) in the period II $(P=0.014)$. Mortality in the last three years is $9 \%$ (2012-2014).

When we evaluated the deaths according to RACHS-1 category, we found that the more complex the procedure, the higher the mortality rate is $(P=0.0001)$, however when analyzing the association between RACHS-1 score and mortality in the two periods separately, we noted a decrease in mortality category in recent years, with the exception of category 6 (Table 2).

In assessing the RACHS-1 score as a predictor of hospital mortality by ROC curve analysis, we find an area of $0.75495 \% \mathrm{Cl}$ (0.727 to 0.78) (Figure 3).

After analyzing the deaths, the vast majority of patients belonged to the category of greater complexity (4 and 6), presenting lower weight and lower age ( $P=0.001$; Table 3$)$.

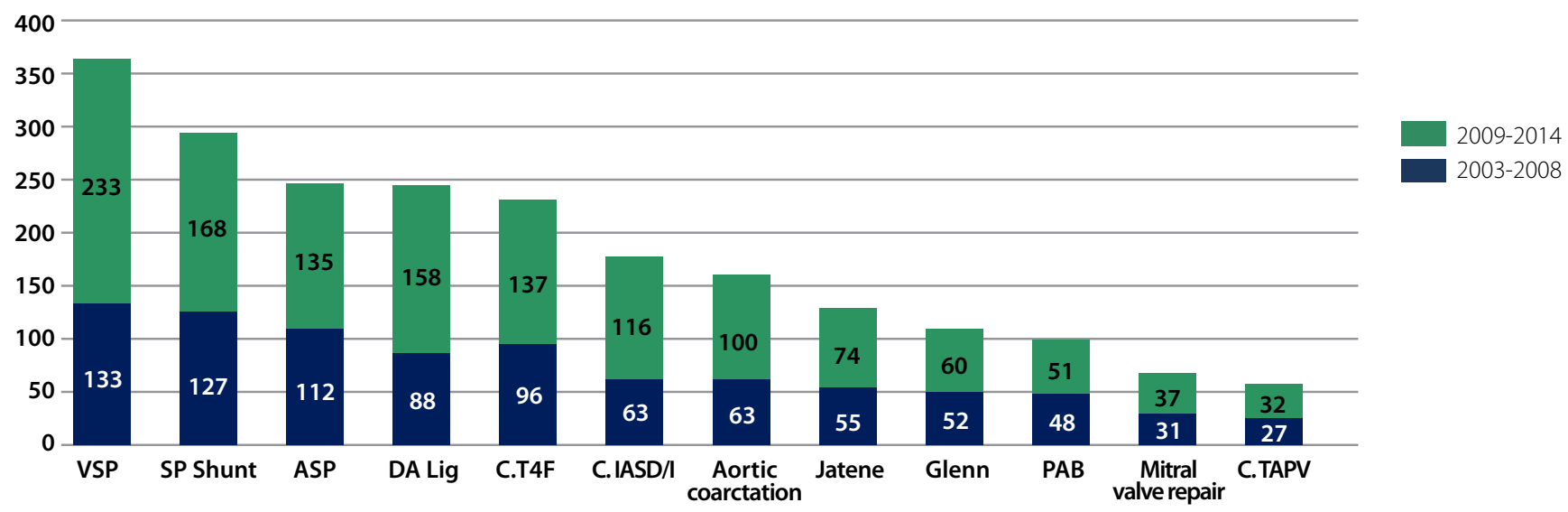

Fig. 2 - Distribution of the procedures according to the nomenclature proposed by RACHS-1 score in both periods. VSP=ventriculoseptoplasty; SP Shunt =systemic-pulmonary shunt; $A S P=$ atrioseptoplasty; DA Lig.=ductus arteriosus ligation; $C$. $T 4 F=$ tetralogy of Fallot correction; $C$. IASD/I=correction of full or intermediate atrioventricular septal defect; $P A B=$ pulmonary artery banding; C. TAPV=correction of total anomalous pulmonary venous

Table 2. Distribution of hospital mortality according to RACHS-1 score categories.

\begin{tabular}{l|c|c|c}
\hline RACHS-1 category & Rate, $(\%)$ & Deaths, $\mathbf{n}(\%)$ & Expected Mortality $\left.\mathbf{( *}^{*}\right)$ \\
\hline Category 1 & $610(19.9)$ & $11(1.8)$ & $0.4 \%$ \\
\hline Category 2 & $1037(33.9)$ & $57(5.5)$ & $3.8 \%$ \\
\hline Category 3 & $1088(35.5)$ & $164(14.9)$ & $8.5 \%$ \\
\hline Category 4 & $277(9.1)$ & $88(32.5)$ & $19.4 \%$ \\
\hline Category 5 & - & - & - \\
\hline Category 6 & $51(1.7)$ & $35(68.6)$ & $47.7 \%$ \\
\hline Total & 3071 & 352 & - \\
\hline
\end{tabular}




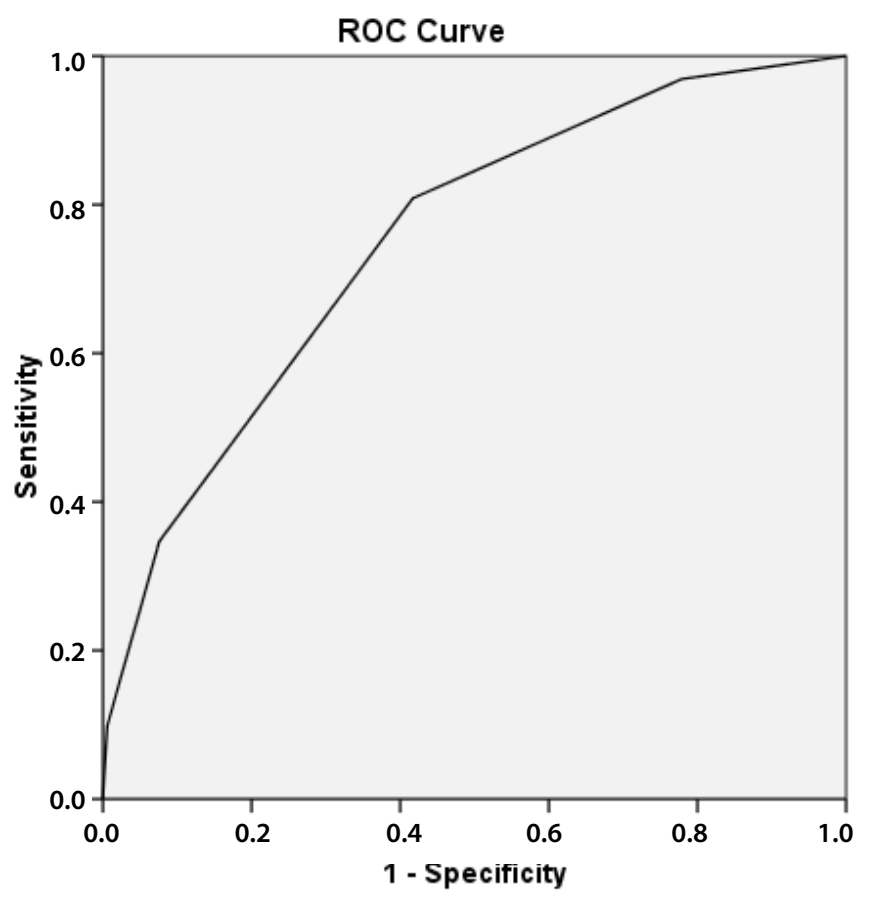

Diagonal segments are produced by ties.

Fig. 3 - Discriminatory ability of RACHS-1 as a predictor of mortality.

We assessed the impact of each variable (RACHS-1 category, age, weight and the period in which the surgery was performed) on the outcome. Adjusting for the severity of the procedure, age, weight and the period in which the surgeries were performed showed direct relationship with the outcome. Children who had undergone surgery in the early years of service and with younger age and weight had higher mortality (OR 0.650, 95\% Cl 0.508 0.831; 4.983 95\% Cl 2.474 -10.038; OR 2.011 95\% Cl 1.546 - 2.616, respectively). The increase in each RACHS-1 category increases the risk of death by $135 \%$ approximately (Table 4).

\section{DISCUSSION}

Congenital heart defects are the most common defects at birth, affecting about $1 \%$ of newborn ${ }^{[1]}$. National epidemiological studies have reported prevalence ranging from 5.94 to 9.58 per 1000 live births. However, few studies have been published with data on operative mortality or in-hospital patients with congenital heart diseases in Brazil[5,6].

Due to the complexity and the high number of surgical procedures for correction of congenital heart diseases, comparisons between hospital or surgical mortality should respect a risk stratification ${ }^{[7]}$, without which, analysis on mortality would be inadequate.

The RACHS-1 score is a simple model that can be applied easily because it requires little data. Despite having some shortcomings as a low individual predictive power and disability of classification of all cardiac procedures ${ }^{[8]}$, it has been widely used to compare mortality among services and to evaluate the evolution of the quality of care provided ${ }^{[9-11]}$

The research presents a series of the Messejana Hospital using RACHS-1 score for evaluation of the results of congenital heart disease treatments. The RACHS-1 score showed a good discriminatory ability for hospital mortality, with an area under ROC curve of 0.754 , similar to previous studies in Brazil (Table 5). Cavalcanti et al. ${ }^{[12]}$ compared three severity scores (RACHS-1, Aristotle and STS-EACTS) of 360 patients operated in Pernambuco and concluded that the three stratification models showed similar discriminatory power for mortality. The total mortality of the sample was $14.7 \%$ with an area under ROC curve for RACHS-1 score of 0.738 (95\% Cl 0.690 to 0.783). In Sergipe, the RACHS-1 score was used to classify 932 procedures performed, with a predominance of category 1 and 2, with a mortality of $8.3 \%$ and area under ROC curve of 0.860 (95\% Cl 0.818 to 0.902$)$ in 10 years of study follow-up ${ }^{[13]}$. Jacobs et al. ${ }^{[9]}$ performed a study review of 47 centers, including 45,635 procedures and found that the higher the complexity the higher the mortality rate was. Larsen et al. ${ }^{[14]}$ applied the RACHS-1 score to rank 957 procedures in Denmark and concluded that it is a good predictor of mortality and length of hospital stay.

Table 3. Analysis of deaths from 2003 to 2014.

\begin{tabular}{|c|c|c|c|}
\hline Variables & Discharge, n (\%) & Deaths, n (\%) & $P$ value \\
\hline $\begin{array}{l}\text { RACHS-1 } \\
\text { Categories 1, } 2 \text { and } 3 \\
\text { Categories } 4 \text { and } 6\end{array}$ & $\begin{array}{c}2503(91.5 \%) \\
205(62.5 \%) \\
\end{array}$ & $\begin{array}{c}232(8.5 \%) \\
123(37.5 \%) \\
\end{array}$ & $<0.0001$ \\
\hline $\begin{array}{l}\text { Weight } \\
\text { Median (IQ) }\end{array}$ & 9 kg $(4.4-19 \mathrm{~kg})$ & $3.85 \mathrm{~kg}(3-7.7 \mathrm{~kg})$ & $<0.0001$ \\
\hline $\begin{array}{l}\text { Age } \\
0 \text { - } 28 \text { days } \\
29 \text { days to } 1 \text { year } \\
1 \text { year to } 12 \text { years } \\
12 \text { years to under } 18 \text { years of age }\end{array}$ & $\begin{array}{c}236(76.8) \\
1015(86.8) \\
1243(93.6) \\
274(95.5)\end{array}$ & $\begin{array}{l}112(32.2) \\
154(13.2) \\
83(6.3) \\
13(4.5)\end{array}$ & $<0.0001$ \\
\hline
\end{tabular}

$\mathrm{IQ}=$ inter-quartile range 
Table 4. Predictors of mortality in multivariate analysis.

\begin{tabular}{l|c|c}
\hline Variable & OR (IC) & P value \\
\hline For each increase of the RACHS-1 category & $2.374(2.074-2.717)$ & 0.0001 \\
\hline Period from 2009 to 2014 & $0.650(0.508-0.831)$ & 0.0001 \\
\hline Age & & 0.0001 \\
0 to 28 days & $4.983(2.474-10.038)$ & 0.004 \\
29 days to 1 year & $2.717(1.388-5.317)$ & 0.035 \\
1 year to 12 years & $2.091(1.054-4.149)$ & \\
12 years to under 18 years of age & & \\
\hline Weight & $2.29(1.673-3.151)$ & 0.0001 \\
0 to $5 \mathrm{~kg}$ & $1.352(0.928-1.970)$ & 0.0001 \\
$5.1-10 \mathrm{~kg}$ & & \\
$>10 \mathrm{~kg}$ & & \\
\hline
\end{tabular}

$\mathrm{Cl}=$ confidence interval (95\%)

Table 5. Summary of Brazilian activities with the use of RACHS-1.

\begin{tabular}{|c|c|c|c|c|c|c|}
\hline Reference & Local & Mortality & $\begin{array}{l}\text { Duration of the study } \\
\text { (years) }\end{array}$ & $\begin{array}{l}\text { No. of } \\
\text { patients }\end{array}$ & ROC curve & $\begin{array}{l}\text { Mortality by } \\
\text { RACHS-1 category }\end{array}$ \\
\hline Mattos et al. ${ }^{[15]}, 2006$ & PE & $14.7 \%$ & 5 & 818 & - & $\begin{array}{l}1 \text { and } 2-8.76 \% \\
3 \text { and } 4-26.12 \% \\
5 \text { and } 6-100 \%\end{array}$ \\
\hline Nina et al. ${ }^{[16]}, 2007$ & MA & $17.2 \%$ & 3 & 145 & - & $\begin{array}{l}1-3.8 \% \\
2-26 \% \\
3-60 \%\end{array}$ \\
\hline DATASUS- São Paulo, $2011^{[17]}$ & SP & $7.1 \%$ & 1 & 974 & - & $\begin{array}{l}1-1.3 \% \\
2-5.1 \% \\
3-10.4 \% \\
4-22.5 \% \\
5-60 \% \\
6-61.1 \%\end{array}$ \\
\hline Leite et al..13], 2012 & PE & $8.2 \%$ & 9 & 932 & 0.860 & $\begin{array}{l}1-0.25 \% \\
2-6.6 \% \\
3-11.1 \% \\
4-62 \% \\
6-100 \%\end{array}$ \\
\hline Cavalcanti et al. ${ }^{[12]}, 2015$ & PE & $14.7 \%$ & 4.5 & 360 & 0.738 & $\begin{array}{l}1-1.3 \% \\
2-11.4 \% \\
3-27.3 \% \\
4-50 \%\end{array}$ \\
\hline Current study, 2016 & CE & $11.6 \%$ & 12 & 3071 & 0.754 & $\begin{array}{l}1-1.8 \% \\
2-5.5 \% \\
3-14.9 \% \\
4-32.5 \% \\
6-68.6 \%\end{array}$ \\
\hline
\end{tabular}

PE=Pernambuco; MA=Maranhão; SP=São Paulo; CE=Ceará 
Although it is a good predictor of mortality, the RACHS-1 score does not address individual and structural factors of a service that can directly affect surgical outcomes. By comparing the data of deaths by category with the rates initially proposed by Jenkins et al. ${ }^{[8]}$, we found that the mortality of the service presents higher levels, but similar to other Brazilian studies (table 5). In a research performed in São Paulo in 2011, the observed mortality was $0.9 \% ; 4.7 \% ; 8.5 \% ; 20.4 \% ; 42.9 \%$ and $50 \%$, in the categories 1 , $2,3,4,5$ and 6 , respectively ${ }^{[17]}$. It is necessary further analysis of the causes of deaths, but some comments can be cited in the evaluation of these numbers.

In developing countries, in addition to the complexity of the procedure, other determinants must be taken into account when assessing the mortality. About $90 \%$ of births worldwide occur in these countries and only a small portion of the population (7\%) have access to treatment of congenital heart disease, by lack of resources in the area, leading to increases in morbidity and mortality ${ }^{[18]}$. This study was performed in a state in Northeastern Brazil, characterized by presenting various social, infrastructure and funding issues ${ }^{[19,20]}$. Due to late diagnosis and poor access to specialized tertiary center, patients are lately referred for surgery. These children usually have severe associated clinical conditions influencing the results as infection, malnutrition, severe cyanosis, ventricular dysfunction, renal dysfunction and pulmonary hypertension. These difficulties were also observed in other studies performed in the same region of the country (Cavalcanti et al.. ${ }^{12]}$, Mattos et al..15], Nina et al.. $\left.{ }^{[16]}\right)$. Considering these aspects, Mattos et al. ${ }^{[15]}$ proposed the creation of a clinical-surgical score to predict intra-hospital mortality in this population. In addition to the complexity of the surgery, they assessed age, nutritional status, associated clinical factors (lung infection, heart failure, cyanosis, acidosis, infection, genetic syndrome, mechanical ventilation and prolonged hospitalization) and time of cardiopulmonary bypass. They concluded that the variables had direct influence on the outcome. In our analysis, we also found association between younger age and lower weight with mortality.

Even with advances in treatment occurred in the last four decades, the in-hospital mortality of our population is still high compared to rates reported in developed countries (Larsen et al..14]; Oster et al.[21]; Nakayama et al.[22]). Despite the use of hospital mortality as a measure for evaluating cardiac surgery programs in adults and children, its use to compare services in pediatric patients is still problematic ${ }^{[23]}$. Welke et al. ${ }^{[24]}$, in a study performed in 2009, concluded that the mortality rate is not a suitable indicator for this purpose because the surgical results depend on many factors.

Our service can be characterized as high volume (250-349 procedures per year) ${ }^{[24]}$. The number of surgeries increased over the last three years to an average of 356.83 procedures/year. With this increase, the mortality rate showed a decrease to $10.5 \%$ and since 2012 is approximately 9\%. These data are in agreement with the literature, which shows an inverse relationship between number of cases of pediatric cardiac surgery and mortality rates, becoming more evident with increasing complexity of the cases ${ }^{[24]}$. Centers with less than 150 cases per year have an increased risk of mortality (OR 1.59) and present worse results in difficult cases when compared to larger services ${ }^{[25,26]}$. However, Welke et al. ${ }^{[24]}$ demonstrated that this discriminatory capacity for mortality was adequate only after adjustment for individual associated risk factors and complexity of the cases, showing that the relationship between surgical volume and mortality is complex and multifactorial.

We observed a higher mortality in the first six years of our service, as well as the number of procedures, the early stage of establishment of a service also has direct influence on the results. There was a significant decrease in mortality in RACHS-1 categories from 1 to 4 in recent years. Mortality rates depend on the infrastructure, the learning curve for surgeons and experience of pediatric cardiologists and multidisciplinary team ${ }^{[18]}$. Nina et al. ${ }^{[16]}$ demonstrated the difficulties faced in the same region of the country in the early years of the service, with high mortality rates even for the simplest procedures. For better results, a highly qualified multi-disciplinary team and adequate institutional funding are required.

This publication had limitations because it is a single-center, retrospective study. Due to the nature of the research, our data were limited and some patients had no information on weight, age and outcome. We could not perform a more detailed analysis of the causes and risk factors associated with mortality. Further studies should be performed in order to understand and improve our results.

\section{CONCLUSION}

The RACHS-1 score has a good ability to discriminate mortality, however, the analysis of mortality in developing countries requires the study of associated clinical factors, as well as structural and technological obstacles in our environment.

\begin{tabular}{|c|c|}
\hline \multicolumn{2}{|c|}{ Authors' roles \& responsibilities } \\
\hline СТMBC & $\begin{array}{l}\text { Conception and design; operations and/or experiments } \\
\text { performance; analysis and/or interpretation of data; } \\
\text { statistical analysis; manuscript writing or critical review } \\
\text { of its content; final approval of the manuscript }\end{array}$ \\
\hline NMGS & $\begin{array}{l}\text { Conception and design; interpretation of data; } \\
\text { manuscript writing or critical review of its content }\end{array}$ \\
\hline VCPJ & $\begin{array}{l}\text { Manuscript writing or critical review of its content; final } \\
\text { approval of the manuscript }\end{array}$ \\
\hline KMPCB & $\begin{array}{l}\text { Manuscript writing and/or critical review of its content; } \\
\text { final approval of the manuscript }\end{array}$ \\
\hline RGP & Manuscript writing and/or critical review of its content \\
\hline ACOT & Final approval of the manuscript \\
\hline $\mathrm{RCC}$ & Operations and/or; final approval of the manuscript \\
\hline GVA & Operations and/or; final approval of the manuscript \\
\hline
\end{tabular}




\section{REFERENCES}

1. van der Linde $D$, Konings EE, Slager MA, Witsenburg M, Helbing WA, Takkenberg JJ, et al. Birth prevalence of congenital heart disease worldwide: a systematic review and meta-analysis. J Am Coll Cardiol. 2011;58(21):2241-7.

2. Pinto Júnior VC, Branco KM, Cavalcante RC, Carvalho Junior W, Lima $J R$, Freitas SM, et al. Epidemiology of congenital heart disease in Brazil. Rev Bras Cir Cardiovasc. 2015;30(2):219-24.

3. Calderón-Colmenero J, Marroquín SR, Salazar JC. Métodos de estratificación de riesgo en la cirugía de cardiopatías congênitas. Arch Cardiol Mex. 2008;78(1):60-7.

4. Jenkins KJ, Gauvreau K, Newburger JW, Spray TL, Moller JH, lezzoni LI. Consensus-based method for risk adjustment for surgery for congenital heart disease. J Thorac Cardiovasc Surg. 2002;123(1):110-8.

5. Guitti JCS. Aspectos epidemiológicos das cardiopatias congênitas em Londrina, Paraná. Arq Bras Cardiol. 2000;74(5):395-9.

6. Amorim LF, Pires CA, Lana AM, Campos AS, Aguiar RA, Tibúrcio JD, et al. Presentation of congenital heart disease diagnosed at birth: analysis of 29,770 newborn infants. J Pediatr (Rio J). 2008;84(1):83-90.

7. Jacobs JP, Edwards FH. Quality improvement and risk stratification for congenital cardiac surgery. In: Sellke FW, Del Nido PJ, Swanson SJ, eds. Sabiston and Spencer Surgery of the chest. 8th ed. Philadelphia: Elsevier Publishing; 2010. p.2105-23.

8. Jenkins KJ, Gauvreau K. Center-specific differences in mortality: preliminary analyses using the Risk Adjustment in Congenital Heart Surgery (RACHS-1) method. JThorac Cardiovasc Surg. 2002;124(1):97-104.

9. Jacobs JP, Jacobs ML, Lacour-Gayet FG, Jenkins KJ, Gauvreau K, Bacha E, et al. Stratification of complexity improves the utility and accuracy of outcomes analysis in a Multi-Institutional Congenital Heart Surgery Database: application of the Risk Adjustment in Congenital Heart Surgery (RACHS-1) and Aristotle Systems in the Society of Thoracic Surgeons (STS) Congenital Heart Surgery Database. Pediatr Cardiol. 2009;30(8):1117-30.

10. Nakayama Y, Shibasaki M, Shime N, Nakajima Y, Mizobe T, Sawa T. The RACHS-1 risk category can be a predictor of perioperative recovery in Asian pediatric cardiac surgery patients. J Anesth. 2013;27(6):850-4.

11. Joshi SS, Anthony G, Manasa D, Ashwini T, Jagadeesh AM, Borde DP, et al. Predicting mortality after congenital heart surgeries: evaluation of the Aristotle and Risk Adjustment in Congenital Heart Surgery-1 risk prediction scoring systems: a retrospective single center analysis of 1150 patients. Ann Card Anaesth. 2014;17(4):266-70.

12. Cavalcanti PE, Sá MP, Santos CA, Esmeraldo IM, Chaves ML, Lins RF, et al. Stratification of complexity in congenital heart surgery: comparative study of the Risk Adjustment for Congenital Heart Surgery (RACHS-1) method, Aristotle basic score and Society of Thoracic Surgeons-
European Association for Cardio-Thoracic Surgery (STS-EACTS) mortality score. Rev Bras Cir Cardiovasc. 2015;30( 2):148-58.

13. Leite DCF, Mendonça JT, Cipolotti R, Melo EV.Tratamento das cardiopatias congênitas em Sergipe: proposta de racionalização dos recursos para melhorar a assistência. Rev Bras Cir Cardiovasc. 2012;27(2):224-30.

14. Larsen SH, Pedersen J, Jacobsen J, Johnsen SP, Hansen OK, Hjortdal V. The RACHS-1 risk categories reflect mortality and length of stay in a Danish population of children operated for congenital heart disease. Eur J Cardiothorac Surg. 2005;28(6):877-81.

15. Mattos SS, Neves JR, Costa MC, Hatem TP, Luna CF. An index for evaluating results in paediatric cardiac intensive care. Cardiol Young. 2006;16(4):369-77.

16. Nina RVAH, Gama MEA, Santos AM, Nina VJS, Figueiredo Neto JA, Mendes VGG, et al. O escore de risco ajustado para cirurgia em cardiopatias congênitas (RACHS-1) pode ser aplicado em nosso meio? Rev Bras Cir Cardiovasc. 2007;22(4):425-31.

17. Ministério da Saúde. [Internet] Sistema de informações hospitalares do SUS (SIH/SUS). [Accessed on: 15/06/2015]. Available at: http:/ w3.datasus. gov.br/datasus/datasus.php.

18. Jenkins KJ, Castañeda AR, Cherian KM, Couser CA, Dale EK, Gauvreau K, et al. Reducing mortality and infections after congenital heart surgery in the developing world. Pediatrics. 2014;134(5):e1422-30.

19. Pinto Júnior VC, Daher CV, Sallum FS, Jatene MB, Croti UA. Situação das cirurgias cardíacas congênitas no Brasil. Rev Bras Cir Cardiovasc. 2004;19(2):IIIVI.

20. Pinto Júnior VC, Fraga MNO, Freitas SM, Croti UA. Regionalização da cirurgia cardiovascular pediátrica brasileira. Rev Bras Cir Cardiovasc. 2013;28(2):256-62.

21. Oster ME, Strickland MJ, Mahle WT. Impact of prior hospital mortality versus surgical volume on mortality following surgery for congenital heart disease. J Thorac Cardiovasc Surg. 2011;142(4):882-6.

22. Nakayama Y, Shibasaki M, Shime N, Nakajima Y, Mizobe T, Sawa T. The RACHS-1 risk category can be a predictor of perioperative recovery in Asian pediatric cardiac surgery patients. J Anesth. 2013;27(6):850-4.

23. Pediatric Congenital Cardiac Surgery in New York State 2002 -2005. Albany: New York State Department of Health; 2007.

24. Welke KF, O'Brien SM, Peterson ED, Ungerleider RM, Jacobs ML, Jacobs $J$ J. The complex relationship between pediatric cardiac surgical case volumes and mortality rates in a national clinical database. J Thorac Cardiovasc Surg. 2009;137(5):1133-40.

25. Spiegelhalter DJ. Mortality and volume of cases in paediatric cardiac surgery: retrospective study based on routinely collected data. BMJ. 2002;324(7332):261-3.

26. Pasquali SK, Li JS, Burstein DS, Sheng S, O'Brien SM, Jacobs ML, et al. Association of center volume with mortality and complications in pediatric heart surgery. Pediatrics. 2012;129(2):e370-6. 